\title{
INGRESSO NO ENSINO FUNDAMENTAL AOS SEIS ANOS? O QUE DIZEM AS CRIANÇAS E SEUS PAIS
}

\author{
ENTRANCE INTO ELEMENTARY SCHOLL AT SIX AGE? WHAT SAY CHILDRENS \\ AND THEIR PARENTS
}

\author{
Caroline RANIRO ${ }^{1}$ \\ Flávia Roberta Velasco CAMPOS ${ }^{2}$
}

RESUMO: Partindo da aprovação da Lei no 11.114, sancionada em 16/05/2005, que estabeleceu que crianças de seis anos fossem então matriculadas no ensino fundamental e da Lei $n^{\circ} 11.274$, sancionada em 06/02/2006 que amplia a duração do ensino fundamental para nove anos e considerando que família e escola são os contextos mais relevantes da vida de uma criança, esse artigo tem por objetivo divulgar parte dos resultados de um estudo que se ocupou também em verificar como pais e crianças concebem o processo de inserção no ensino fundamental aos seis anos de idade. $\mathrm{O}$ estudo, de caráter qualitativo, se fundamenta na abordagem bioecológica de desenvolvimento humano de Bronfenbrenner (1996), cuja ênfase está na interconexão entre vários níveis do sistema ecológico. Foram realizadas entrevistas semi-estruturadas com quinze crianças e seus pais, para apreender as percepções dos sujeitos envolvidos com o ingresso no ensino fundamental. Os locais das entrevistas foram uma escola de esfera municipal de uma cidade do interior paulista para crianças e a própria residência para a maioria dos pais. A coleta de dados revelou que pais e crianças em sua maioria concordam com a inserção no ensino fundamental aos seis anos de idade. Todos pareceram habituados ao novo modelo e satisfeitos com resultados prévios que este já pôde oferecer. Os alunos pareceram manter um relacionamento satisfatório na escola, estão motivados, interessados e desejam ler e escrever - expectativa que vai ao encontro do que afirmam pais e embora às vezes as crianças apresentem cansaço, elas valorizam e têm clareza da importância do processo de ensino-aprendizagem. Frequentar a educação infantil parece ter contribuído para a adaptação no ensino fundamental. O contexto familiar revela pais que valorizam e se interessam pela escolarização dos filhos, procurando acompanhá-los, mesmo quando o ambiente familiar é atingido por situações adversas. Os resultados obtidos certamente contribuirão para a Educação Escolar, principalmente porque ainda são poucos os estudos que consideraram o primeiro ano do ensino fundamental de nove anos, possibilitando a manifestação dos principais envolvidos nele, as crianças.

PALAVRAS-CHAVE: Perspectiva bioecológica. Crianças de seis anos. Ensino fundamental de nove anos.

ABSTRACT: From the approval of the Law 11.114, published in 05/16/2005, which established enrolment in elementary school from children with six years, from Law 11.274, published in 02/06/2006, which extends the duration of elementary school for nine years and

1 Universidade Estadual Paulista (Unesp), Faculdade de Ciências e Letras, Araraquara - SP - Brasil. Doutoranda no Programa de Pós-Graduação em Educação Escolar. E-mail: carolraniro@yahoo.com.br.

${ }^{2}$ Universidade Estadual Paulista (Unesp), Faculdade de Ciências e Letras, Araraquara - SP - Brasil. Mestranda no Programa de Pós-Graduação em Educação Escolar. E-mail: flavelasco@yahoo.com.br. 
considering family and school with relevant figures to the life of the children, this article is aimed to divulge partial results with how understand parents and himself about insertion process of children with six years in the elementary school. This study is a qualitative nature and based in bioecological perspective of human development established by Bronfenbrenner (1996), whose emphasizes the interconnection between various levels of the ecological system. Semi-structured interviews were conducted with fifteen children and their parents, to understand perceptions of the individuals when entrance into elementary school. The interviews locations were a municipal school located in one city of the Sao Paulo State and the own residence of the parents. The data collection illustrated, predominantly, that parents and children agree with the insertion with six years in the elementary school. All seemed to have grown accustomed to the new model and are satisfied with previous results that it can offer nowadays. The students seemed to maintain a satisfactory relationship in school, are motivated, interested and want to read and write, an expectation that meets with parents affirmation. Whilst, sometimes, the children are tired, they value and have clarity of the importance of teaching-learning process. Attend the early childhood education seems to have contributed to the adaptation in elementary school. The family context reveals parents that are value and interested in the education of the children, trying to follow them, even when the family environment and disadvantaged by adverse situations. The results will certainly contribute to the Education School, mainly because there are few studies that considered the first year of elementary school for nine years, allowing the manifestation of the main people involved, the children.

KEYWORDS: Bioecological perspective. Children of six years. Elementary school for nine years.

\section{Introdução}

Os primeiros anos do século XXI, no âmbito das políticas educacionais, foram marcados pela promulgação de leis que alteram a estrutura, funcionamento e organização do ensino fundamental.

O Ministério da Educação, através do Conselho Nacional de Educação, com sua função orientadora e normativa, tem desenvolvido ações com o intuito de apoiar os sistemas de ensino, elaborando documentos que apresentam as diretrizes norteadoras para a reorganização do ensino fundamental de nove anos, expressos em um breve histórico.

Em 2004, o MEC definiu como uma de suas prioridades a ampliação do ensino fundamental obrigatório com início aos seis anos e coordenou, juntamente com a União Nacional dos Dirigentes Municipais (Undime) e o Conselho Nacional dos Secretários de Educação (Consed), a organização de sete encontros regionais com a participação de diretores, supervisores, coordenadores pedagógicos, professores e outros profissionais da educação para discutir a viabilidade da implementação desta medida no âmbito nacional dos sistemas de ensino (RANIRO, 2009). 
Em julho deste mesmo ano, foi elaborado pelo Departamento de Políticas de Educação Infantil e do Ensino Fundamental o documento "Ensino Fundamental de Nove Anos: Orientações Gerais”, produzido pela Secretaria de Educação Básica e resultado de discussões apresentadas nos encontros regionais promovidos pelo MEC. Tal documento é referência para questões pedagógicas, administrativas e de avaliação no que se refere à inclusão das crianças de seis anos no ensino fundamental. Ele ainda apresenta argumentos para ampliação do ensino fundamental de nove anos, a fundamentação legal desta proposta, dados de Censo Demográfico - que corroboram para reforçar o propósito de tal ampliação e indica o formato para organização do Ensino Fundamental de nove anos com o acesso de alunos de seis anos de idade. Para garantir uma nomenclatura comum às múltiplas possibilidades de organização desse nível de ensino (séries, ciclos, outros - conforme art.23 da LDB nº 9.394/96) as Orientações Gerais do ensino fundamental lançadas em 2004 - sugerem que ele seja assim mencionado: Anos iniciais ( $1^{\circ}$ ao $5^{\circ}$ ano) e Anos Finais ( $6^{\circ}$ ao $9^{\circ}$ ano). Crianças de seis anos estariam cursando dentro da nova perspectiva, o $1^{\circ}$ ano dos anos iniciais do ensino fundamental.

Ainda de acordo com tais orientações, o objetivo do ensino fundamental obrigatório de nove anos é "[...] assegurar a todas as crianças um tempo mais longo de convívio escolar, maiores oportunidades de aprender e, com isso, uma aprendizagem mais ampla." (BRASIL, 2004, p.17).

O segundo capítulo ainda deste relatório discorre acerca das particularidades dos alunos de seis anos de idade. Considera que suas características, experiências, direitos, necessidades, formas de interação, interesses e outros precisam ser levados em conta por pais e profissionais da educação. Sugere a contextualização dessas crianças de seis anos para que de fato, a aprendizagem seja inclusiva e considera que a elas deve ser oferecido um ambiente alfabetizador e motivador do ensino de leitura e escrita (RANIRO, 2009).

O terceiro e último capítulo das orientações gerais indicam como deve ser a organização do trabalho pedagógico em escolas que oferecerem o ensino fundamental de nove anos. Sugere que as escolas reorganizem suas estruturas como um todo e invoca a possibilidade dos sistemas de ensino induzirem e estimularem linhas de ação coletiva nas escolas, “[...] intencionalmente voltadas para a construção de um projeto pedagógico que reflita o desejo e o planejamento de cada comunidade escolar", de forma que todos os envolvidos possam levantar princípios, objetivos, metas, refletindo sobre eles e se comprometendo com aquilo que for considerado relevante para a escola (BRASIL, 2004, 
p.23). Apresenta-se como relevante diagnosticar a realidade local e valorizar o percurso histórico percorrido na escola, sistematizando resultados.

Em 16 de maio de 2005 foi sancionada a Lei $n^{\circ} 11.114$ que alterou apenas um dos aspectos da LDB: a idade de matrícula das crianças (de sete para seis anos), mas manteve a exigência de duração mínima do ensino fundamental em oito anos letivos. Entretanto, segundo Abreu (2006, p. 43),

\begin{abstract}
Antecipar o ingresso no ensino fundamental para seis anos sem ampliar a duração desse nível de ensino para nove anos seria um contra-senso. Ao alterar a idade própria do ensino fundamental para seis a treze anos, essa mudança não contribuiria para o sucesso escolar dos alunos. Ao contrário, aumentaria as dificuldades para tal sucesso.
\end{abstract}

Ainda em 2005, o Parecer do Conselho Nacional de Educação CNE/CEB nº 18 , vem estabelecer a garantia às crianças que ingressam aos seis anos no Ensino Fundamental em ao menos nove anos de estudo e enfatiza que cada sistema de ensino precisa promover adequação do projeto pedagógico escolar, inclusive definindo se o primeiro ano ou os primeiros anos de estudo se destina (m) ou não a alfabetização dos alunos (FEIJÓ, 2006).

Uma nova Lei, a n⿳亠丷厂 11.274 (BRASIL, 2006a), promulgada no início do ano seguinte, manteve a matricula no ensino fundamental aos seis anos de idade; porém ampliou a duração do ensino fundamental para nove anos. Tal Lei ainda garantiu ao Poder Público um prazo de até 2010 para sua implementação pelos municípios, estados e Distrito Federal.

No novo modelo, as pré-escolas - segmento da educação infantil - passam a atender crianças de quatro e cinco anos de idade. Com a aprovação desta lei, mais crianças vêm sendo incluídas no sistema educacional brasileiro desde então.

No mesmo ano, o MEC publica um manual nomeado Ensino Fundamental de Nove Anos - orientações para a inclusão da criança de seis anos de idade (+ 1 ano é fundamental) (BRASIL, 2006b). Esse documento abarca textos que apresentam orientações pedagógicas que considerem a infância como período que se estende dos seis aos dez anos de idade e ainda levem em conta o desenvolvimento e aprendizagem das crianças de seis anos ingressantes no ensino fundamental. Em geral, os nove textos escritos por autores como Sônia Kramer, Ângela Meyer Borba, Cecília Goulart, entre outros estudiosos de renome - apresentam mais reflexões, embora também algumas possibilidades de trabalho nos primeiros anos do ensino fundamental de nove anos.

Segundo Fernandes (2008), os documentos oficiais apontam que a ampliação do Ensino Fundamental, assegurando a entrada da criança de seis anos, consiste em uma 
estratégia para possibilitar aos pequenos educandos um maior tempo de convívio escolar e isso por sua vez promove melhor qualidade e oportunidades de aprendizagem aos alunos, além de contribuir para as experiências de vida destes sujeitos.

Quanto à prática diária propriamente dita exercida no primeiro ano do novo ensino fundamental, o terceiro relatório elaborado pelo MEC (BRASIL, 2006c) proclama que não se trata de repetir atividades que vinham sendo então desenvolvidas no último ano da educação infantil agora no primeiro ano do ensino fundamental e nem sequer de exclusivamente alfabetizar as crianças.

Quanto aos conteúdos a serem ministrados no primeiro ano, consultando os documentos oficiais firmados pelo MEC, Martins e Arce (2007, p. 38-39) verificaram que tais documentos

[...] afirmam que o ensino fundamental deva ser repensado em seu conjunto, no que se inclui a revisão dos projetos político-pedagógicos; especialmente no que se referem à concepção de infância, alfabetização, letramento, desenvolvimento humano, [...], organização do processo de aprendizagem, metodologias de ensino, organização do tempo escolar e currículo; definição de políticas de formação continuada; instalações físicas etc.

Portanto, não se trata de manter ou adequar os conteúdos até então transmitidos aos alunos da $1^{\mathrm{a}}$ série do ensino fundamental de oito anos. O PNE reconhece que essa antecipação “[...] requer planejamento e diretrizes norteadoras para o atendimento integral da criança em seu aspecto físico, psicológico, intelectual e social, além de metas para a expansão do atendimento, com garantia de qualidade". (BRASIL, 2004, p.15).

Um dos documentos publicados pelo MEC sinaliza que “[...] quando as crianças ingressam na instituição escolar antes dos sete anos de idade, apresentam, em sua maioria, resultados superiores em relação àquelas que ingressam somente aos sete anos." (BRASIL, 2006b, p.3)

Entretanto é evidente que a maior aprendizagem não depende do aumento do tempo de permanência na escola, mas sim do emprego mais eficaz do tempo. No entanto, a associação de ambos deve contribuir significativamente para que os educandos aprendam mais.

Em setembro de 2009, é publicado o documento intitulado Ensino fundamental de nove anos: passo a passo do processo de implantação (BRASIL, 2009), onde se reitera a necessidade de se debater a proposta de ampliação, assim como a formação de professores, infraestrutura, recursos didático-pedagógicos tendo como prioridade o sucesso escolar.

São apresentados nesse documento os objetivos intrínsecos a proposta de tal ampliação, quais sejam: 
a) melhorar as condições de equidade e de qualidade da Educação Básica; b) estruturar um novo ensino fundamental para que as crianças prossigam nos estudos, alcançando maior nível de escolaridade; c) assegurar que, ingressando mais cedo no sistema de ensino, as crianças tenham um tempo mais longo para as aprendizagens da alfabetização e do letramento. (BRASIL, 2009, p. 5).

Considerando tais publicações e determinações legais, o presente trabalho visa apresentar parte dos resultados de uma pesquisa de mestrado que deu voz à crianças e seus familiares acerca da inserção dos alunos no primeiro ano do Ensino Fundamental, etapa que agora integra um ciclo de alfabetização, denominado pelos documentos oficiais de "ciclo da infância”, período que compreende os três primeiros anos da educação básica, com foco central na alfabetização e no letramento (CONSELHO NACIONAL DE EDUCAÇÃO, 2010).

Ao discutir como vem ocorrendo o ingresso da criança de seis anos no Ensino Fundamental é preciso compreender como sofrem e percebem esse processo os principais atores envolvidos. Portanto, o estudo que originou esta publicação abarca percepções que crianças e seus pais apresentam mediante a situação atual do ensino fundamental promovida pela reforma educacional que alterou não só a idade de ingresso, como também ampliou em mais um ano este nível de escolarização. Buscou-se captar a percepção destes sujeitos diretamente incluídos na questão para entender de forma mais completa, o fenômeno a ser pesquisado. Sendo o aluno o principal atingido pela política pública, torna-se imprescindível que ele participe efetivamente de pesquisas desta natureza, contribuindo para tal.

Acreditando que os primeiros anos de vida são cruciais para o desenvolvimento de um indivíduo, é extremamente relevante estudar os impactos das alterações de políticas públicas na vida daqueles que são pequenos educandos e dos principais sujeitos que os acompanham na vida, seus pais - para a produção do conhecimento científico em Educação (RANIRO, 2009).

A análise do estudo que aqui se apresenta está baseada na perspectiva bioecológica de Bronfenbrenner (1996), que considera a pessoa, o processo, o contexto e o tempo - como elementos fundamentais à pesquisa em desenvolvimento humano.

Esta perspectiva refere-se ao estudo científico da acomodação mútua e progressiva entre um ser humano ativo em desenvolvimento e as propriedades mutantes dos ambientes imediatos nos quais ele vive, conforme o processo é afetado pelas relações desses ambientes e pelos contextos mais amplos em que ele está inserido (BRONFENBRENNER, 1996).

$\mathrm{O}$ autor defende, portanto, que o entendimento do desenvolvimento humano requer o exame de sistemas de interação de múltiplas pessoas em um ou mais ambientes e concebe 
esse ambiente ecológico "[...] como uma série de estruturas encaixadas, uma dentro da outra." (BRONFENBRENNER, 1996, p. 5) e esclarece que ele é formado por microssistema, mesossistema, exossistema e o macrossistema.

O microssistema é o ambiente imediato onde a pessoa em desenvolvimento se encontra e também as pessoas que interagem com ela diretamente: família, escola e programas educativos freqüentados pela criança são exemplos desse nível de ambiente.

$\mathrm{O}$ mesossistema inclui inter-relações entre dois ou mais ambientes nos quais a pessoa em desenvolvimento participa ativamente (relações entre microssistemas). O estudo da relação entre a família e instituição educacional ocorre neste nível de ambiente ecológico.

Já o exossistema atinge a pessoa em desenvolvimento de forma restrita ou indireta; onde ela possui acesso limitado, raramente estando presente. E o macrossistema, se refere

[...] a consistências, na forma e conteúdo de sistemas de ordem inferior [acima citados] que existem, ou poderiam existir, no nível da sub-cultura ou da cultura como um todo, juntamente com qualquer sistema de crença ou ideologia subjacente a essas consistências. (BRONFENBRENNER, 1996, p.21).

Essas consistências presentes no dia-a-dia dos sujeitos também influenciam seu desenvolvimento - assim como, por exemplo, as leis 11.114/05 e 11.274/06, que aprovaram o ingresso de crianças de seis anos no ensino fundamental e ampliaram o ensino fundamental de nove anos - causando impacto na vida e conseqüentemente no desenvolvimento de todas as crianças brasileiras.

Todos os níveis são de fundamental importância - assim como as inter-relações entre eles. Qualquer evento que ocorra em quaisquer dos sistemas acima citados - serão relevantes para o desenvolvimento do ser humano.

É uma perspectiva que considera o tempo, os processos do desenvolvimento e os contextos em que os sujeitos estão envolvidos, as condições e histórias de vida destes, os processos ativos que ocorrem nestes ambientes e na sociedade como um todo (KOLLER, 2004) O desenvolvimento consiste, portanto “[...] em um processo de interação recíproca entre a pessoa e o seu contexto através do tempo, [...]" (NARVAZ; KOLLER, 2004, p.57) e se define então como uma junção de forças que surgem de diferentes contextos e de relações entre eles - podendo tanto apresentar estabilidade quanto mudanças nas características biopsicológicas dos seres humanos em sua vida presente ou futura. 
Segundo Bronfenbrenner (1996, p. 9, grifo do autor), “[...] a ciência básica precisa da política pública ainda mais do que a política pública precisa da ciência básica."

O conhecimento e a análise das políticas públicas são essenciais para o progresso da pesquisa em ciência desenvolvimental porque chamam a atenção do investigador para aspectos do ambiente imediatos e remotos, que são críticos para o desenvolvimento cognitivo, emocional e social da pessoa.... Ao examinar o impacto das questões políticas publicas na pesquisa básica sobre o desenvolvimento humano, é essencial distinguir as interpretações fundamentadas na evidência empirica daquelas enraizadas em uma preferência ideológica. (BRONFENBRENNER, 2011, p.91).

Um documento do MEC em que trata das perspectivas referentes à implantação e organização do ensino fundamental de nove anos tece afirmações análogas, elucidando que compartilha, de certa forma, desta mesma concepção de desenvolvimento:

O desenvolvimento maior ou menor desses aspectos e as possibilidades de aprendizagem dessas crianças são determinados pelas experiências e pela qualidade das interações às quais se encontram expostas no meio sociocultural em que vivem ou que frequentam. Daí o papel decisivo da família, da escola e dos professores, como mediadores culturais no processo de formação humana das crianças. (BRASIL, 2004, p. 20).

O ingresso no ensino fundamental é considerado um momento muito importante para o desenvolvimento da criança - em termos de aquisição de conhecimentos, comportamentos e valores. A socialização e a autonomia também estão presentes. Ingressar no ensino fundamental significa uma série de mudanças para a criança em relação à: convivência, brincadeiras, apoio dos adultos, concentração, aquisição de conhecimento. A criança tem que se ajustar a essas e outras coisas que podem variar conforme a instituição de ensino ou não, como a questão do tempo, por exemplo, e estará desenvolvendo comportamentos característicos do papel de aluno - novo papel social - reflexo da transição da educação infantil para o ensino fundamental. Mudanças de papéis alteram a maneira pela qual a pessoa é tratada, como ela age, o que faz e inclusive o que pensa e sente. Na transição de um nível para o outro, as crianças assumem o papel de aluno e ao mesmo tempo em que experimentam esse papel, continuam a ser crianças, carregando consigo necessidades de novas adaptações assim como as aprendizagens já adquiridas, de modo que essa dinâmica precisa ser objeto de atenção dos profissionais nessa etapa da escolaridade para além do entendimento de que essa é uma ruptura necessária (LOLLATO, 2000; COLELLO, 2003; SANTOS, 2006) 
Enquanto a educação infantil permanece com seu caráter histórico de educação informal, o ensino fundamental se institui como educação escolar e marca definitivamente o vínculo do aluno com a vida estudantil (MARTINS; ARCE, 2007)

Santos (2006) em sua pesquisa verifica que são muitas as mudanças que ocorrem para a criança na primeira série e levanta alguns indicadores entre tantos outros existentes, de ruptura entre a pré-escola e o inicio do ensino fundamental que merecem destaque:1) a mudança de um espaço físico já conhecido para outro a ser conhecido: localização da escola, da sala, distâncias, tamanhos, organização e funcionamento diferentes e o uso de mesas e cadeiras individuais, com menor mobilidade ao longo do dia; 2) o agrupamento: aumento do número de crianças por turma, crianças novas na própria sala ou na escola como um todo, com características diferentes, tamanhos, idades, hábitos, comportamentos; 3) a rotina: redução do tempo para brincar, aumento do tempo que permanecem sentados em atividades dirigidas, divisão do tempo por áreas do conhecimento, introdução da avaliação do desempenho escolar e exclusão do apreciado "dia do brinquedo"; 4) interações: a relação de autoridade entre professores e crianças e entre as crianças passa a ser referenciada, principalmente em relação ao desempenho acadêmico.

A situação não é nova somente para as crianças. Elas, suas famílias e as pessoas que atuam na escola também precisam se adaptar. Pouco a pouco, todos os envolvidos neste processo vão descobrindo seus novos parceiros do dia-a-dia. As crianças e as famílias vão conhecendo e se adaptando aos professores, metodologia, estrutura escolar, novos colegas, novas tarefas, e outros. E a escola assume o desafio de criar vínculos entre crianças, pais e educadores. "Ela recebe mais que novas pessoas. Recebe a cultura, o hábito, a história delas. Todos acabam mudando." (ROSSETI-FERREIRA; VITÓRIA; GOULARDINS, 1998, p.44).

O ingresso da criança na escola de ensino fundamental - é um importante momento para as reações futuras dela em seus passos de progresso na vida. É um período importante não só para criança, mas como para sua família, professores e escola. O processo de adaptação do aluno a esse novo contexto é mediado por essas instâncias e além: pelos próprios companheiros que a criança passa a conhecer.

Todos os níveis da educação básica são extremamente importantes para o desenvolvimento humano. Portanto, é preciso identificar as especificidades presentes em cada nível e aproximar o sujeito da situação na qual esteja inserido favorecendo suas interações.

\section{Método}


Este artigo apresenta dados de uma pesquisa que se ocupou em analisar, entre outras questões, como quinze crianças e seus familiares concebem a inserção aos seis anos de idade no primeiro ano do Ensino Fundamental. Foram realizadas entrevistas semi-estruturadas com crianças matriculadas em três classes de primeiro ano de uma escola pública municipal do interior de São Paulo - e com seus pais. As entrevistas foram conduzidas por roteiros previamente elaborados, que apresentavam questões chaves - mas que se ajustavam às condições e falas dos entrevistados.

Seguem abaixo os quadros 1 e 2, que caracterizam os participantes do referido estudo:

Quadro 1: Caracterização das crianças

\begin{tabular}{|c|c|c|c|}
\hline Identificação & Ano & Sexo & $\begin{array}{l}\text { Histórico de escolarização no momento da realização } \\
\text { da pesquisa }{ }^{3}\end{array}$ \\
\hline $\mathrm{C}^{4}{ }^{4}$ & $1^{\circ} \mathrm{A}$ & Feminino & Frequenta a $4^{\mathrm{a}}$ escola entre públicas e particulares \\
\hline $\mathrm{C} 2$ & $1^{\circ} \mathrm{A}$ & Feminino & Frequenta a $3^{\text {a }}$ escola, todas públicas \\
\hline $\mathrm{C} 3$ & $1^{\circ} \mathrm{A}$ & Feminino & Frequenta a $3^{\mathrm{a}}$ escola entre públicas e particulares \\
\hline $\mathrm{C} 4$ & $1^{\circ} \mathrm{A}$ & Feminino & Frequenta a $2^{\mathrm{a}}$ escola, ambas públicas \\
\hline C5 & $1^{\circ} \mathrm{A}$ & Feminino & Frequenta a $2^{\mathrm{a}}$ escola, ambas públicas \\
\hline C6 & $1^{\circ} \mathrm{A}$ & Masculino & Frequenta a $2^{\mathrm{a}}$ escola, ambas públicas \\
\hline $\mathrm{C} 7$ & $1^{\circ} \mathrm{A}$ & Feminino & Frequenta a $3^{\text {a }}$ escola, todas públicas \\
\hline $\mathrm{C} 8$ & $1^{\circ} \mathrm{A}$ & Masculino & Frequenta a $2^{\mathrm{a}}$ escola, ambas públicas \\
\hline C9 & $1^{\circ} \mathrm{B}$ & Feminino & Frequenta a $4^{\mathrm{a}}$ escola entre públicas e particulares \\
\hline $\mathrm{C} 10$ & $1^{\circ} \mathrm{B}$ & Masculino & Frequenta a $2^{\mathrm{a}}$ escola, ambas públicas \\
\hline C11 & $1^{\circ} \mathrm{B}$ & Feminino & Frequenta a $2^{\mathrm{a}}$ escola, ambas públicas \\
\hline C12 & $1^{\circ} \mathrm{C}$ & Masculino & Frequenta a $5^{\mathrm{a}}$ escola entre públicas e particulares \\
\hline $\mathrm{C} 13$ & $1^{\circ} \mathrm{C}$ & Feminino & Frequenta a $2^{\mathrm{a}}$ escola, ambas públicas \\
\hline $\mathrm{C} 14$ & $1^{\circ} \mathrm{C}$ & Masculino & Frequenta a $3^{\mathrm{a}}$ escola entre públicas e particulares \\
\hline $\mathrm{C} 15$ & $1^{\circ} \mathrm{C}$ & Feminino & Frequenta a $2^{\mathrm{a}}$ escola, ambas públicas \\
\hline
\end{tabular}

Fonte: Elaboração própria.

${ }^{3}$ Informação transmitida à pesquisadora pelos familiares das crianças.

${ }^{4} \mathrm{~A}$ letra $\mathrm{C}$ refere-se à criança. 
Das quinze crianças participantes, todas são advindas de camadas populares. Oito frequentavam o primeiro ano $\mathrm{A}$, três o primeiro ano $\mathrm{B}$, e quatro o primeiro ano $\mathrm{C}$. Todas elas tinham seis anos completos no momento da coleta de dados, sendo dez meninas e cinco meninos. Todas as crianças já haviam frequentado escola antes do ingresso no primeiro ano do Ensino Fundamental. Uma das crianças já estava à época da pesquisa, frequentando a quinta escola. Duas frequentando a quarta escola, quatro frequentando a terceira escola, e oito crianças frequentando a segunda escola.

Quadro 2: Caracterização dos familiares entrevistados ${ }^{5}$

\begin{tabular}{|c|c|c|c|c|c|}
\hline $\begin{array}{l}\text { Criança/ } \\
\text { Família }\end{array}$ & $\begin{array}{l}\text { Principal } \\
\text { (ais) } \\
\text { entrevistado } \\
\text { (s) }\end{array}$ & Profissão & $\begin{array}{l}\text { Idade do } \\
\text { entrevistado }\end{array}$ & $\mid \begin{array}{lr}\text { Grau } & \text { de } \\
\text { instrução } & \text { dos } \\
\text { entrevistados }\end{array}$ & $\begin{array}{l}\text { Estado civil } \\
\text { dos } \\
\text { entrevistados }\end{array}$ \\
\hline $\mathrm{C} 1 / \mathrm{F} 1$ & Mãe & Dona de casa & 27 anos & Ensino Médio & Amasiado \\
\hline $\mathrm{C} 2 / \mathrm{F} 2$ & Mãe & $\begin{array}{l}\text { Controladora de } \\
\text { seguro }\end{array}$ & 27 anos & Ensino Médio & Solteira \\
\hline $\mathrm{C} 3 / \mathrm{F} 3$ & Pai & $\begin{array}{l}\text { Operador } \quad \mathrm{de} \\
\text { materiais }\end{array}$ & 30 anos & $\begin{array}{l}\text { Ensino Superior } \\
\text { Incompleto }\end{array}$ & Amasiado \\
\hline $\mathrm{C} 4 / \mathrm{F} 4$ & Mãe & Dona de casa & 30 anos & $\begin{array}{l}\text { Ensino } \\
\text { Fundamental } \\
\text { Incompleto }\end{array}$ & Casada \\
\hline $\mathrm{C} 5 / \mathrm{F} 5$ & Mãe & Dona de casa & 41 anos & Ensino Médio & Casada \\
\hline C6/F6 & Mãe & Cabeleireira & 39 anos & Técnico & Divorciada \\
\hline $\mathrm{C} 7 / \mathrm{F} 7$ & Mãe & Dona de casa & 28 anos & $\begin{array}{l}\text { Ensino Médio } \\
\text { Incompleto }\end{array}$ & Amasiada \\
\hline $\mathrm{C} 8 / \mathrm{F} 8$ & Mãe & Cabeleireira & ---------------- & Técnico & Casada \\
\hline C9/F9 & Mãe & Dona de casa & 32 anos & $\begin{array}{l}\text { Ensino } \\
\text { Fundamental }\end{array}$ & Casada \\
\hline $\mathrm{C} 10 / \mathrm{F} 10$ & Mãe & Zeladora & 26 anos & -------------------- & Casada \\
\hline \multirow[t]{2}{*}{$\mathrm{C} 11 / \mathrm{F} 11$} & Pai & $\begin{array}{l}\text { Operador } \\
\text { manufatura }\end{array}$ & 38 anos & Ensino Médio & \multirow[t]{2}{*}{ Casados } \\
\hline & Mãe & Doméstica & 37 anos & Ensino Médio & \\
\hline
\end{tabular}

5 As famílias pertencem à classes populares. Não foi possível coletar todas as informações com todos os envolvidos. O contexto familiar é aqui retratado no quadro conforme a fala do(s) familiar (es) entrevistado (s). ${ }^{6}$ Algumas entrevistas, embora tiveram um sujeito principal, foram contempladas também por comentários de outros sujeitos. Considera-se como principal (ais) entrevistado (s) àquele (s) cuja participação foi mais intensa durante a entrevista. 


\begin{tabular}{|c|c|c|c|c|c|}
\hline \multirow[t]{2}{*}{$\mathrm{C} 12 / \mathrm{F} 12$} & Pai & $\begin{array}{l}\text { Gerente } \\
\text { financeiro }\end{array}$ & 42 anos & $\begin{array}{l}\text { Ensino Superior } \\
\text { em curso }\end{array}$ & \multirow[t]{2}{*}{ Casados } \\
\hline & Mãe & $\begin{array}{l}\text { Auxiliar } \\
\text { administrativo }\end{array}$ & 37 anos & Ensino Médio & \\
\hline C13/F13 & Mãe & $\begin{array}{l}\text { Auxiliar } \\
\text { produção }\end{array}$ & 32 anos & $\begin{array}{l}\text { Ensino Médio } \\
\text { Incompleto }\end{array}$ & Casada \\
\hline $\mathrm{C} 14 / \mathrm{F} 14$ & Mãe & Doméstica & 35 anos & ---------------- & Amasiada \\
\hline $\mathrm{C} 15 / \mathrm{F} 15$ & Mãe & Dona de casa & 42 anos & $\begin{array}{l}\text { Ensino } \\
\text { Fundamental }\end{array}$ & Amasiada \\
\hline
\end{tabular}

Fonte: Elaboração própria.

Das quinze famílias entrevistadas, doze foram representadas exclusivamente por mães, duas por casais (pai e mãe) e uma por pai. As entrevistas foram realizadas nas residências dos entrevistados. A idade dos participantes varia de 27 a 42 anos.

Optou-se pela investigação naturalista, de abordagem qualitativa - a qual tem como objetivo questionar os sujeitos para apreender como experimentam suas vivências, o modo como interpretam as suas experiências e como estruturam o mundo social em que vivem e dessa forma tenta captar as perspectivas dos participantes.

Todas as entrevistas foram gravadas - uma vez que isso permite captação imediata de todas as expressões orais - e o tempo entre elas varia bastante. A gravação direta, ainda segundo Biasoli-Alves (1998) visa auferir maior preservação do discurso do entrevistado e evitar seu comprometimento. Posteriormente, as entrevistas foram uma a uma minuciosamente transcritas na íntegra.

A análise das entrevistas seguiu as etapas abaixo descritas:

Diversas leituras dos dados coletados até a impregnação desses pelo pesquisador;

Busca de regularidades, padrões e tópicos presentes nos dados;

Criação de categorias de codificação dos dados para que os resultados pudessem ser sistematizados.

Independente da análise das falas dos sujeitos pesquisados - os valores, os significados, concepções, opiniões destes - foram tratados com respeito e consideração.

\section{Resultados e discussão}

Esta pesquisa revelou que a maioria das famílias se posicionou a favor da inserção de crianças de seis anos no Ensino Fundamental. E elas próprias - as principais envolvidas - 
revelaram estar adaptadas, motivadas, satisfeitas e interessadas por estar cursando o primeiro ano do Ensino Fundamental.

C14 - O primeiro ano é legal assim, tem muitas crianças, os professores são legais, as lição do primeiro ano também é, né?

Segundo documento do MEC,

Especificamente em relação à linguagem escrita, a criança, nessa idade ou fase de desenvolvimento, que vive numa sociedade letrada, possui um forte desejo de aprender, somado ao especial significado que tem para ela frequentar uma escola. (BRASIL, 2004, p. 19).

As famílias falam que as crianças estão adaptadas e motivadas ao primeiro ano e que adoram a escola: não pedem e não gostam de atrasar ou faltar às aulas, gostam da professora, dos amigos, dos funcionários e da merenda, estão apresentando um bom desempenho, gostam e querem fazer lição de casa com responsabilidade e chegam da escola contando com empolgação o que lá fizeram durante a tarde. Duas famílias disseram que nas férias seus filhos "não vêem a hora" de voltar pra escola.

F5 - Ela ta super contente com a escola. [...] Ainda tem dia que ela fala: "mãe a gente não fez quase nada de lição". Então você vê que não é aquela coisa puxada, né?

F2 - [...] Ela chora pra ir. Ela teve caxumba e queria ir pra escola [...] não quer ficar em casa. [...] Ela chega contando tudo o que fez na escola, como que foi, sabe? Sempre ta querendo levar alguma coisa pra mostrar pra professora, ou quer trazer as coisas pra mostrar pra nós. [...]

$\mathrm{P}^{7}-$ E ela ta gostando dessa escola nova? Ela fala isso pra vocês?

F2 - Fala. Ta gostando.

F14 - [...] nossa... Ele chega em casa e eu ainda falo: "vai tomar banho!". Não. Primeiro é a lição. Eu falo: "mas come alguma coisa!". Não. Tem que fazer a lição. Então a primeira coisa é a lição.

F4 - [...] As férias inteiras ela foi pra biblioteca da escola...

As crianças ainda declararam bom desempenho e dedicação no primeiro ano. Não foram detectados grandes problemas e/ou dificuldades para o enfrentamento dos desafios que o novo ano oferece: mudanças no espaço físico, agrupamentos diferentes de alunos, alteração na rotina e quantidade das tarefas, interações, e outras (SANTOS, 2006). Além disso, pareceram estar obtendo sucesso na nova fase: estão adaptados aos conteúdos e práticas 
educativas utilizadas pelas professoras. Cuidam dos materiais, sentem-se motivados a aprender, gostam e querem fazer as lições solicitadas, entendem a proposta de ensino do primeiro ano e desejam ler e escrever. Pelos depoimentos delas e dos seus pais, é possível inferir que há o predomínio para o ensino dos conteúdos de Língua Portuguesa: leitura e escrita. Os alunos alegaram que a escola de Ensino Fundamental é um espaço mais amplo; que proporciona lições desafiadoras que permitem o aprendizado da leitura e escrita. $\mathrm{O}$ principal motivo e a grande novidade neste contexto mais sistematizado em relação ao anterior é o fato de que nesta nova escola, as crianças aprendem a ler e a escrever: "fazem lições".

As famílias concordam. Muitas afirmaram que o filho já está lendo e escrevendo ou que está se empenhando para isso, indo à biblioteca pegar livros ou soletrando e tentando compreender dizeres nas placas que encontram pelas ruas ou estabelecimentos. Verificou-se em relação ao trabalho que vem sendo realizado no primeiro ano, que as famílias em geral, estão satisfeitas com o ensino que é oferecido.

F1 - Acho que ela ta aprendendo tudo, acho que ela ta aproveitando bem. Ela ta lendo. Nossa [...]

Entre os pontos positivos da escola, as crianças elencaram: a biblioteca, o parque, o recreio, os amigos, a educação física, a comida e em maioria, a oportunidade de estudar, lições e a professora. Entre os pontos negativos apareceram: muita coisa para escrever, colegas de classe, ir para diretoria e em grande maioria brigas com colegas (incluindo bater, xingar). Quatro crianças se mostraram plenamente contentes com tudo o que a escola lhes oferece e afirmaram que não tem nada que não gostem neste espaço e que, portanto, não gostariam que a escola mudasse em nada.

$\mathrm{P}$ - O que você gosta de estudar?

C15 - O cabeçário... E os números.

$\mathrm{P}-[\ldots] \mathrm{E}$ o que você não gosta $[\ldots]$ ?

C15 - De fazê bagunça e batê nos colegas.

$\mathrm{P}-[\ldots]$ Você queria que essa escola fosse diferente?

C15 - Não.

P - Não? Em nada? Você acha que está bom do jeito que está?

C15 - Sim.

C12 - Eu amo aprendê a lê, escreve... Eu gosto de vim pra escola... [...] Eu amo vim pra escola. [...] O que eu gosto é aprendê. A lê e escrevê.

$\mathrm{P}-[\ldots]$ E o que você não gosta? Tem alguma coisa que você não gosta na escola?

C12 - Deixa eu pensá...[...]

C12 - De brigá.[...] 
$\mathrm{P}-\mathrm{E}$... Você queria que essa escola fosse diferente? [...]

C12 - Não.

P - Não. Pra você está bom do jeito que está?

C12 - Tá.

Já uma das crianças revelou que o que a incomoda na escola é a quantidade das tarefas - que ela julga ser em demasia. E alega que "dói a mão", de tanto escrever.

$\mathrm{P}-\mathrm{E}$ o que você mais gosta na sua escola?

C11 - Hum... eu acho que o parquinho, né?

$\mathrm{P}-$ Parquinho...

C11 - Hum... mais o parquinho. [...]

$\mathrm{P}-[\ldots]$ E você gosta de fazer as lições?

C11 - Há, mais ou menos... Quando foi umas três, quatro, eu gosto. Mai quando foi um monte.... Eu.... Dói a minha mão.

Embora somente esta criança tenha revelado para pesquisadora o cansaço devido à quantidade de tarefas de sala de aula, parece que a C1 já se queixou em casa também segundo relato da sua família:

F1 - Ela ficou um pouquinho mais cansada, é porque ela fala assim: "mãe, agora a gente escreve muito". Ela fala isso.

As famílias se posicionaram a favor da antecipação do ingresso no Ensino Fundamental. A F12 chegou a dizer que o primeiro ano está sendo uma experiência ótima e muitas outras relataram as vantagens que a mudança pôde proporcionar para os filhos: a criança está "mais esperta"; "com a mente fresca para aprender"; "as crianças hoje estão mais evoluídas"; "quando antes entrar pra escola, menos eles se acomodam"; "a vontade de aprender aumentou", "mostram vontade de ler e escrever"; entre outras proposições.

Entretanto, os pais apresentaram pouca clareza do processo de inserção no primeiro ano e do funcionamento desta nova proposta. Demonstraram confusão no entendimento do que é de fato esse primeiro ano e do que ele representa em termos de escolaridade, e confundiram a nomenclatura "primeiro ano" com "primeira série".

Em relação ao ingresso dos alunos na escola pesquisada, a prefeitura municipal realizou um sorteio de vagas entre as famílias interessadas e todos os entrevistados tinham esta escola como sua primeira opção para matrícula de seus filhos - ficando então plenamente satisfeitos com o resultado do sorteio. Pelos depoimentos dos familiares, foi possível apreender ainda que eles se preocuparam em preparar os filhos para a transição de nível de ensino. Explicaram, conversaram, passaram informações, incentivaram, motivaram, foram 
criando expectativas sobre o novo contexto. Provavelmente com o intuito de orientá-los e, assim minimizar o impacto para possíveis mudanças.

F1 - Sempre conversamos. A gente passava aqui na frente [se referindo à escola] e eu já falava pra ela: "olha a escola que você vai estudar" [...] F8 - Conversei com ele. Falei que aqui não era só brincar, que ele tinha que prestar mais atenção, obedecer a professora, que ele tinha que aprender, que era o primeiro ano, [...] Eu expliquei.

A notícia da antecipação escolar chegou às famílias por meio das diretoras e professoras das CEMEIs ${ }^{8}$. Algumas mães principalmente se "assustaram" inicialmente, mas sendo esclarecidas pelas CEMEIs e vivenciando o momento junto com os filhos puderam perceber que eles se adaptaram muito rapidamente, e foram se tranqüilizando.

F14 - [...] quando foi no pré, que falo que ia vim com seis anos eu entrei em desespero. Falei: "Meu Deus!" Mas nossa,... Ele ta pegando bem. [...] $\mathrm{P}$ - Você concorda com essa mudança?

F14 - Ah, eu concordei sim. [...] se ele não conseguisse acompanhar talvez eu pensasse diferente né? Não sei. Pra ele deu certo, foi bom. Acho que se ele ficasse mais um ano fazendo o pré sem aprender ele ia enjoar. Que ele tem aquela coisa pra lê. Sempre quis lê.

F12 - [...] No caso dele eu acho que foi positivo sim. Eu fiquei apreensiva. Falei: "Gente! Ele ainda é um bebê meu e já vai aprender a escrever! Como é que uma criança vai sentar numa sala e ficar horas, [...]? Tem que ter mais alguma outra coisa, senão eles não vão aguentar!” E me parece que tem. Então eu não tenho queixa.

Cerca de quatro famílias se mostraram contrárias à antecipação do ingresso de sete para seis anos de idade no ensino fundamental. Mas apesar disso, admitem que seus filhos vêm apresentando sucesso, já sabem escrever, querem e gostam de ir pra escola, de fazer lições de casa e estão interessados pelo aprendizado da leitura e da escrita. Justamente essas famílias revelam mais enfaticamente a falta de entendimento quanto à proposta do ensino fundamental de nove anos e apresentam-se confusas quanto à compreensão conceitual do primeiro ano.

F4 - Porque eu não entendi muito ainda... Primeiro ano e primeira série... Qual é a diferença?

F8 - [...] Cê saía do prezinho sabendo escrever, antes era assim... cê saía do pré escrevendo, quando cê ia pro primeiro ano, cê ia preparada. Agora não. Vai pro primeiro ano, é como se fosse um pré, mas um pré mais sério.

${ }^{8}$ CEMEI - Centro Municipal de Educação Infantil. 
F13 - [...] Pra mim, eu não vi muito objetivo da escola hoje, ou do governo, ter feito um parquinho, na realidade, na escola. [...]

F1 - Eu entendi que só mudou que o que tinha no prezinho, que veio pra escola. Eu entendi que foi só isso.

Os pais ainda não apresentam clareza sobre a obrigatoriedade do ensino se configurar somente a partir do Ensino Fundamental. Alguns revelaram que acreditavam que o pré também seria obrigatório ou que frequentá-lo seria condição mínima para o ingresso no Ensino Fundamental. Eles mostraram que valorizam a escolarização e se empenham em compreender os processos que ali ocorrem. Porém, é preciso que as famílias sejam mais bem preparadas quanto a questões de ordem legal.

Essa pesquisa revela ainda que famílias de camadas populares, prioritariamente representadas pelas mães, mesmo quando apresentam rotinas atarefadas e relações conturbadas, se interessam e se empenham na busca de se envolver em assuntos escolares seja em casa - em auxílios em tarefas escolares, acompanhando materiais - ou na escola, por meio de festividades ou reuniões.

F1 - [...] A gente ta pegando livro, eu venho com ela na biblioteca pra pegar o livro, nas férias eu venho com ela, aí ela já ta lendo o livro sozinha, então eu acho que hoje já ta aprendendo bastante. [...]

Passar de uma escola para outra não acarretou em sofrimento para as crianças: elas demonstram gostar da nova escola, se empolgaram para falar sobre ela, não choraram, nem apresentaram recusa em frequentar ou estranharam em demasia este novo contexto. Naturalmente, segundo os pais, demonstraram ansiedade, euforia, preocupações, desejos. Uma única família revelou que o filho apresentou a preocupação de não encontrar mais os amigos na nova escola. E outra, que em exceção, disse que "o sentimento deve ter sido de grande novidade. O negócio é sério. Ele sentiu diferença sim.” (F8)

C6 - Foi bem legal vir estudar aqui.

Segundo documento oficial:

É necessário que o sistema escolar esteja atento às situações envolvidas no ingresso da criança no Ensino Fundamental, seja ela oriunda diretamente da família, seja da pré-escola, a fim de manter os laços sociais e afetivos e as condições de aprendizagem que lhe darão segurança e confiança. Continuidade e ampliação - em vez de ruptura e negação do contexto socioafetivo e de aprendizagem anterior - garantem à criança de seis anos que 
ingressa no Ensino Fundamental o ambiente acolhedor para enfrentar os desafios da nova etapa. (BRASIL, 2004, p.20).

Dessa forma, o acesso à pré-escola por todas as crianças entrevistadas parece ter sido um diferencial que contribuiu para o enfrentamento desses desafios - uma vez que elas já possuíam, portanto, minimamente, noções básicas de funcionamento e estrutura escolar. Além disso, ambas as escolas (anterior e atual) localizam-se no mesmo bairro e integram o sistema de ensino municipal, e isto, de certa forma as aproxima - fatores que podem ter corroborado para minimização de adversidades na nova realidade que lhes foi apresentada. Algumas crianças já haviam frequentado por mais de um ano a educação infantil - em uma ou mais escolas - o que se conclui já se estarem apropriadas de instituições escolares.

Outro fator que pôde favorecer a adaptação é o fato de alguns colegas de turma na CEMEI se reencontrarem no primeiro ano, mesmo que em classes diferentes - o que significa que num primeiro momento eles podem se sentir acolhidos e não únicos num ambiente que embora estranho/diferente não estava servindo só a eles, mas a outros que eles conheciam previamente. Sob a perspectiva bioecológica, experiências anteriores podem afetar as futuras, e, nesta perspectiva por apresentarem um histórico de escolarização anterior, pode-se dizer que as crianças já trazem para o Ensino Fundamental disposições apreendidas.

A experiência escolar anterior ao ingresso no ensino formal, além de estar implicada com aquisições básicas de leitura e escrita, também encontra-se relacionada ao desenvolvimento de habilidades sociais que facilitam o enfrentamento de situações adversas pela criança. (FERREIRA, 2005, p. 139)

Espaço físico, trabalho docente, organização de rotinas e horários, e outros fatores do primeiro ano, agradam crianças e seus pais - que pareceram se ajustar a mudanças invocadas pelo novo contexto, sem grandes conturbações.

Nesta pesquisa, sujeitos pesquisados e envolvidos com o primeiro ano pareceram satisfeitos com os resultados que ele vem oferecendo, uma vez que atribuíram valor positivo a ele.

Autores como Abreu (2006), Batista (2006) e Marangon (2007) acreditam que ampliar o Ensino Fundamental e inserir crianças de seis anos nesta etapa de escolarização foi uma decisão acertada do governo Federal. Batista (2006) sinaliza que dessa forma, a escola pode cumprir mais eficazmente seus papéis. Segundo ele, essa instituição agora dispõe de mais tempo para socializar as crianças, para inseri-las num novo universo cultural e criar mais oportunidades de aprendizado - permitindo que mais educandos se beneficiem de políticas 
públicas que visem melhorar a qualidade do ensino. Além disso, defende que crianças que entram mais cedo na escola tendem a alcançar maior escolaridade, que o tempo mais estendido para o ensino fundamental pode favorecer condições mais adequadas para alfabetizar e enfatiza a importância de medidas de redução do abismo que ainda separa educação infantil e ensino fundamental. Marangon (2007) publica em uma revista voltada para professores, argumentos a favor da ampliação do ensino fundamental de nove anos: a socialização desde cedo, ganho de qualidade na educação, inclusão de crianças de qualquer classe social à alfabetização, aumento nas oportunidades profissionais futuras, diminuição do número de analfabetos funcionais. E enfatiza que é preciso rever questões de ordem pedagógica e administrativa. Abreu (2006, p.43) conclui: “[...] essa é uma mudança que vale a pena, no sentido da construção de escola de qualidade para todos os brasileiros!"

Este trabalho teve como objetivo verificar como pais e crianças concebem a inserção no primeiro ano, já que são os principais envolvidos por uma política pública que determinou o ingresso mais precoce no ensino fundamental.

Para atender às demandas do problema e objetivo de pesquisa, foi adotada a perspectiva bioecológica de Bronfenbrenner (1996) que se mostrou adequada, pois se constitui em uma abordagem que considera processos, pessoas, contextos e tempo em todas as suas complexidades. O autor acredita ainda ser de extrema importância compreender a percepção do sujeito sobre os contextos e as interações - algo que vai exatamente ao encontro do que essa pesquisa se propôs. Logicamente que não é possível em um único trabalho satisfazer todos os critérios da pesquisa ecológica. Com o intuito de compreender de forma relacional o primeiro ano, a pesquisa considerou os principais contextos onde se insere a criança: família e escola - microssistemas nos quais existem padrões de atividades, papéis sociais e relações interpessoais vivenciados pelo sujeito em questão. Quem vivencia um contexto é que pode revelar como o percebe e qual significado o atribui (BRONFENBRENNER, 1996).

Adotou-se ainda tal perspectiva do desenvolvimento humano por julgá-la pertinente ao investir em estudos que abordem as relações entre ciência e políticas públicas.

As tentativas em apreender percepções sobre a inserção de crianças de seis anos no Ensino Fundamental apontam para um avanço na ciência em busca de constatar os efeitos de uma medida educacional que acreditou ser assertiva, mas que ainda não tinha sido verificada sob a ótica que esta pesquisa propôs. 


\section{Considerações finais}

Ampliar o ensino fundamental acarreta mudanças não só pra este nível de ensino como também para educação infantil. Serão necessários esforços para que as descontinuidades entre essas duas instâncias sejam diminuídas, a cooperação entre os professores seja ampliada e as práticas pedagógicas revistas, nos dois âmbitos.

O objetivo deste artigo era apresentar os resultados de uma pesquisa que ouviu crianças e seus pais sobre o processo de inserção no Ensino Fundamental que vem ocorrendo de forma mais precoce no Brasil desde 2006. Frente aos resultados encontrados, é possível dizer que este trabalho atingiu ao proposto e permite derivar ou ampliar outros direcionamentos para diferentes abordagens de pesquisa cientifica.

É muito válido considerar que atualmente crianças de camadas populares vêm tendo oportunidades de escolarização que antes eram oferecidas apenas a classes restritas da sociedade brasileira, por meio do sistema particular de ensino. Destaca-se ainda a importância da articulação entre o primeiro ano já implantado com os anos que se seguem, uma vez que se trata de três anos que integram o ciclo de alfabetização. Nesse sentido, se fazem necessárias outras pesquisas que se dediquem a estudos desse período tão singular, com suas características e particularidades, de modo a constatar a efetivação dos objetivos propostos pela legislação para esse ciclo, bem como se complementam os primeiros anos com os segundos e terceiros.

Outra proposta é acompanhar crianças de primeiro ano nos próximos anos do Ensino Fundamental a fim de verificar se a adaptação, a motivação e o interesse pela escola se mantêm no curso do tempo. Acreditando que o conhecimento é contínuo e mutável e que os dados aqui apresentados não podem ser generalizados, é possível ainda replicar a produção deste estudo em outras realidades em outros momentos, ou produção de artigos que revelem estudos que ampliam o universo de participantes desta pesquisa contemplando também professores envolvidos com a questão.

Este artigo se torna pertinente ao campo da Educação porque permite divulgar a análise dos impactos de duas leis que foram instituídas acreditando serem assertivas, e que foram a partir de um estudo, verificadas sob um aspecto bastante particular. Assim, é possível obter dados um pouco mais significativos dessa política de implementação do Ensino Fundamental a partir dos seis anos de idade, bem como sua ampliação de oito para nove anos. 


\section{REFERÊNCIAS}

ABREU, M. Mudanças na educação - nova lei altera o ingresso e a permanência no Ensino Fundamental. Revista do professor, Porto Alegre, n.87, p.42-43, jul./set. 2006.

BATISTA, A. A. G. Ensino fundamental de nove anos: um importante passo à frente. Boletim UFMG, Belo Horizonte, v.32, n.1522, mar. 2006. Disponível em: <http://www.ufmg.br/boletim/bol1522/segunda.shtml>. Acesso em: 25 dez. 2008.

BIASOLI-ALVES, Z. M. M. A pesquisa psicológica - análise de métodos e estratégias na construção de um conhecimento que se pretende científico. In: ROMANELLI, G. (Org.). Diálogos metodológicos sobre prática de pesquisa. Ribeirão Preto: Legis Summa, 1998. p.135-157.

BRASIL. Ministério da Educação. Secretaria de Educação Básica. Ensino fundamental de nove anos: passo a passo do processo de implantação. 2.ed. Brasília, 2009.

BRASIL. Lei n ${ }^{\circ} 11.274$, de 6 de fevereiro de 2006. Altera a redação dos arts. 29, 30, 32 e 87 da Lei no 9.394, de 20 de dezembro de 1996, que estabelece as diretrizes e bases da educação nacional, dispondo sobre a duração de 9 (nove) anos para o ensino fundamental, com matrícula obrigatória a partir dos 6 (seis) anos de idade. Diário Oficial da União: República Federativa do Brasil, Brasília, DF, 6 fev. 2006a.

BRASIL. Ministério da Educação. Ensino fundamental de nove anos: orientações para a inclusão da criança de seis anos de idade (+ 1 ano é fundamental). Brasília: FNDE: Estação Gráfica, 2006b.

BRASIL. Ministério da Educação. Secretaria de Educação Básica. Ampliação do ensino fundamental para nove anos $-3^{\circ}$ Relatório. Brasília, 2006c. Disponível em: <http://portal.mec.gov.br/seb/arquivos/pdf/relatorio_internet.pdf>. Acesso em: 10 out. 2008.

BRASIL. Ministério da Educação. Secretaria de Educação Básica. Ensino fundamental de nove anos: orientações gerais. Brasília, 2004.

BRONFENBRENNER, U. Bioecologia do desenvolvimento humano: tornando os seres humanos mais humanos. Porto Alegre: ARTMED, 2011.

BRONFENBRENNER, U. A ecologia do desenvolvimento humano: experimentos naturais e planejados. Porto Alegre: ARTMED, 1996.

COLELLO, S. M. G. Educação e intervenção escolar. Revista Internacional d'humanitats, Barcelona, v.4, p.47-56, 2003. Disponível em: 〈http://www.hottopos.com/rih4/silvia.htm>. Acesso em: 23 jul. 2007.

CONSELHO NACIONAL DE EDUCAÇÃO. Define Diretrizes Curriculares Nacionais Gerais para a Educação Básica. Resolução no 4, de 13 de julho de 2010. Diário Oficial da União: República Federativa do Brasil, Brasília, DF, 9 jul. 2010.

FEIJÓ, P. C. B. Ampliação do ensino fundamental para nove anos de duração e a matricula aos seis anos de idade: aspectos administrativos, jurídicos e práticos. Jus Navigandi, 
Teresina, v.11, n.1250, 3 dez. 2006. Disponível em:

<http://jus2.uol.com.br/doutrina/texto.asp?id=9238>. Acesso em: 27 out. 2007.

FERNANDES, F. C. Política de ampliação do ensino fundamental para nove anos: pela inclusão das crianças de seis anos de idade na educação obrigatória. Disponível em:

$<$ http://portal.mec.gov.br/seb/arquivos/pdf/Ensfund/chagas_ensfundnovanos.pdf > . Acesso em: 25 dez.2008.

FERREIRA, M. de C. T. As tarefas de desenvolvimento da meninice e a transição para o ensino fundamental. 2005. Tese (Doutorado em Ciências, Área: Psicologia) - Faculdade de Filosofia, Ciências e Letras, Universidade de São Paulo, Ribeirão Preto, 2005.

KOLLER, S. H. (Org.). Ecologia do desenvolvimento humano: pesquisa e intervenção no Brasil. São Paulo: Casa do Psicólogo, 2004.

LOLLATO, S. O. Família e escola: vivências e concepções de pais, professores e crianças de primeira série do ensino fundamental. 2000. 125f. Dissertação (Mestrado em Educação Escolar) - Faculdade de Ciências e Letras, Universidade Estadual Paulista, Araraquara, 2000.

MARANGON, C. O direito de aprender. Revista Nova Escola, São Paulo, v.22, n.208, dez. 2007. Disponível em: <http://acervo.novaescola.org.br/politicas-publicas/legislacao/direitoaprender-425381.shtml>. Acesso em: 05 dez. 2016.

MARTINS, L. M.; ARCE, A. (Org.). A educação infantil e o ensino fundamental de nove anos. In: MARTINS, L. M.; ARCE, A. Quem tem medo de ensinar na Educação Infantil. Campinas: Alínea, 2007. p.37-62.

NARVAZ, M. G.; KOLLER, S. H. O modelo bioecológico do desenvolvimento humano. In: KOLLER, S. H. (Org.). Ecologia do desenvolvimento humano: pesquisa e intervenção no Brasil. São Paulo: Casa do Psicólogo, 2004. p.55-69.

RANIRO, C. Um retrato do primeiro ano do ensino fundamental: o que revelam crianças, pais e professoras. 2009. Dissertação (Mestrado em Educação Escolar) - Faculdade de Ciências e Letras, Universidade Estadual Paulista, Araraquara, 2009.

ROSSETI-FERREIRA, M.; VITORIA, T.; GOULARDINS, L. Quando a criança começa a freqüentar a creche ou pré-escola. In: ROSSETI-FERREIRA, M. et al. (Org.). Os fazeres na educação infantil. São Paulo: Cortez, 1998. p.43-47.

SANTOS, K. C. dos. Autonomia da criança: transição da educação infantil para o ensino fundamental, conforme as prescrições oficiais. 2006. Dissertação (Mestrado em Educação: História, Política, Sociedade) - Pontifíca Universidade Católica de São Paulo, São Paulo, 2006. 


\section{Como referenciar este artigo}

RANIRO, Caroline.; CAMPOS, Flávia Roberta Velasco. Ingresso no ensino fundamental aos seis anos? O que dizem as crianças e seus pais. Doxa: Rev. Bras. Psicol. Educ., Araraquara, v.19, n.1, p. 84-106, jan./jun. 2017. ISSN: 1413-2060.

Submetido em: 05/02/2017

Aprovado em: 05/04/2017 